\title{
Bonding and morphology study of carbon nitride films obtained by dual ion beam sputtering
}

Cite as: Journal of Vacuum Science \& Technology A 18, 515 (2000); https://doi.org/10.1116/1.582218 Submitted: 06 August 1999 . Accepted: 26 November 1999. Published Online: 03 March 2000

C. Quirós, P. Prieto, A. Fernández, E. Elizalde, C. Morant, R. Schlögl, O. Spillecke, and J. M. Sanz

\section{ARTICLES YOU MAY BE INTERESTED IN}

BN and ZrN AES Spectra Obtained by Depth Profiling of ZrN/BN Multilayers

Surface Science Spectra 7, 86 (2000); https://doi.org/10.1116/1.1288819

Epitaxial growth of $\mathrm{LiCOO}_{2}$ thin films with (001) orientation

AIP Advances 7, 115011 (2017); https://doi.org/10.1063/1.4999833

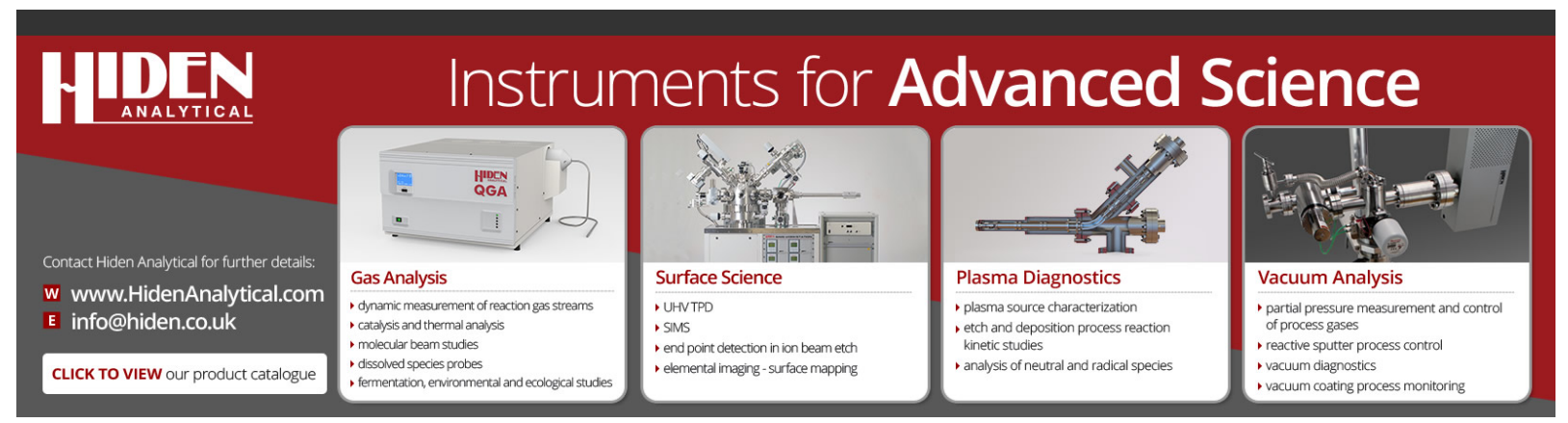




\title{
Bonding and morphology study of carbon nitride films obtained by dual ion beam sputtering
}

\author{
C. Quirós and P. Prieto \\ Department of Applied Physics C-XII, Universidad Autónoma de Madrid, Cantoblanco, \\ E-28049 Madrid, Spain \\ A. Fernández \\ Institute of Material Science of Seville (CSIC-University of Seville), Isla de la Cartuja, \\ E-41092 Seville, Spain \\ E. Elizalde and C. Morant \\ Department of Applied Physics C-XII, Universidad Autónoma de Madrid, Cantoblanco, E-28049 Madrid, \\ Spain \\ R. Schlögl and O. Spillecke \\ Fritz-Haber-Institut der Max-Planck-Gesellschaft, Abteilung Anorganische Chemie, \\ D-14195 Berlin, Germany \\ J. M. Sanz ${ }^{\text {a) }}$ \\ Department of Applied Physics C-XII, Universidad Autónoma de Madrid, Cantoblanco, \\ E-28049 Madrid, Spain
}

(Received 6 August 1999; accepted 26 November 1999)

Thin carbon-nitrogen films (i.e., $\mathrm{CN}_{x}$ ) have been obtained by dual ion beam sputtering. The chemical composition and the type of bonding of the $\mathrm{CN}_{x}$ material have been examined, as a function of the deposition parameters, by Fourier transform infrared spectroscopy, x-ray photoelectron spectroscopy (XPS), and electron energy loss spectroscopy (EELS). The high concentration of $\mathrm{C} \equiv \mathrm{N}$ bonds present in some of the samples, as stated by FT-IR, allowed us to correlate this type of bonding with some of the features observed in the corresponding XPS and EELS spectra. Nitrogen concentrations of up to 45 at. \%, depending on the deposition conditions, have been estimated by XPS and EELS. The films deposited at low energy were rather homogeneous, as demonstrated by Auger electron spectroscopy depth profiling, and show the highest $\mathrm{C}-\mathrm{N}$ simple bonds concentration. On the contrary, the use of high energy assisting nitrogen ions leads to the formation of carbonitrile groups (i.e., $\mathrm{C} \equiv \mathrm{N}$ ), as well as resputtering effects that significantly reduce the thickness of the films and even hinder the growth of a film. The topography and morphology of the different films, as determined by atomic force microscopy, were also observed to depend on the conditions of assistance. (c) 2000 American Vacuum Society.

[S0734-2101(00)03002-5]

\section{INTRODUCTION}

Stimulated by the theoretical work of Liu and Cohen, ${ }^{1,2}$ nitrogenated carbon films, i.e., $\mathrm{CN}_{x}$, have been the subject of numerous studies in the last few years. Liu and Cohen theoretically predicted the existence of $\beta-\mathrm{C}_{3} \mathrm{~N}_{4}$, a stable phase with a bulk modulus and mechanical properties comparable to those of diamond. In $1993 \mathrm{Niu}$ et $\mathrm{al}^{3}{ }^{3}$ reported the synthesis of small $\mathrm{C}_{3} \mathrm{~N}_{4}$ crystallites by laser vaporization of graphite using a $\mathrm{N}^{+}$beam to bombard the growing film. Since then, a large number of studies ${ }^{3-12}$ have been published, describing different approaches to grow carbon nitride films using different experimental methods. $\mathrm{CN}_{x}$ films have been prepared by reactive magnetron sputtering, ${ }^{4,5}$ ion beam deposition, ${ }^{6}$ dual ion beam sputtering, ${ }^{7}$ electron cyclotron resonance plasma assisted vapor deposition, ${ }^{8}$ plasma en-

a) Author to whom correspondence should be addressed; electronic mail: josem.sanz@uam.es hanced chemical vapor deposition (CVD), ${ }^{9,10}$ ion implantation, ${ }^{11}$ and laser ablation under nitrogen ion beam bombardment. ${ }^{3,12}$ The resulting films were predominantly amorphous with a maximum nitrogen content of up to 45 at. \%, i.e., the films are always carbon rich films. A few authors have also reported nanometer-sized $\beta-\mathrm{C}_{3} \mathrm{~N}_{4}$ crystallites, that appeared dispersed in an amorphous $\mathrm{CN}_{x}$ matrix. ${ }^{3,10,13}$ Dawei et al. ${ }^{10}$ have reported large area polycrystalline $\mathrm{C}_{3} \mathrm{~N}_{4}$ films on $\mathrm{Si}(111)$ by rf plasma enhanced CVD using various transition layers. To date, samples with sufficient amounts of crystallized $\mathrm{C}_{3} \mathrm{~N}_{4}$ and with mechanical properties comparable to the predicted values have not been reported. In spite of that, the $\mathrm{CN}_{x}$ films still have potential applications as hard, low friction wear resistant coatings. ${ }^{14-16}$

More recently Liu and Wentzcovitch ${ }^{17}$ pointed out the existence of three $\mathrm{C}_{3} \mathrm{~N}_{4}$ phases; the hexagonal, the defect cubic zincblende, and the rhombohedral phase, whose cohesive energies lie close to each other and also close to those of 
TABLE I. Energy and current density $J_{N}$ of the $\mathrm{N}_{2}^{+}$ions used to assist the deposition of carbon nitride films, ion to atom arrival rate ratio (ARR) and averaged atomic composition $[\mathrm{N}] /[\mathrm{C}]$ as determined by XPS and EELS.

\begin{tabular}{cccccc}
\hline \hline Sample & $\begin{array}{c}\text { Energy } \\
(\mathrm{eV})\end{array}$ & $\begin{array}{c}J_{N} \\
\left(\mathrm{~mA} / \mathrm{cm}^{2}\right)\end{array}$ & $\begin{array}{c}\mathrm{ARR} \\
{\left[\mathrm{N}_{2}^{+} / \mathrm{Cl}\right]}\end{array}$ & $\begin{array}{c}{[\mathrm{N}] /[\mathrm{C}]} \\
(\mathrm{XPS})\end{array}$ & $\begin{array}{c}{[\mathrm{N}] /[\mathrm{C}]} \\
(\mathrm{EELS})\end{array}$ \\
\hline $\mathrm{A} 0$ & 0 & $\ldots$ & 0 & 0 & - \\
$\mathrm{A} 1$ & 55 & 0.031 & 1.25 & 0.32 & 0.2 \\
$\mathrm{~A} 2$ & 65 & 0.055 & 2.26 & 0.38 & - \\
$\mathrm{A} 3$ & 71 & 0.066 & 2.71 & 0.41 & - \\
$\mathrm{A} 4$ & 73 & 0.072 & 2.96 & 0.49 & 0.6 \\
$\mathrm{~A} 5$ & 76 & 0.077 & 3.16 & 0.51 & 1.0 \\
$\mathrm{~A} 6$ & 87 & 0.083 & 3.41 & 0.58 & \\
\hline \hline
\end{tabular}

diamond and graphite. For applications as hard coatings, the growth of graphite-like carbon and of the rhombohedral carbon nitride structure, which are soft phases, should be hindered. Therefore the determination of the chemical structure of the films has become a critical issue in the characterization of these films, where not only the stoichiometry but also the bonding structure have to be determined. The characterization of $\mathrm{CN}_{x}$ films is an actual problem, where the absence of standard reference samples is a handicap. X-ray photoelectron spectroscopy (XPS) and infrared (IR) are the most widely used techniques to obtain information about the stoichiometry and type of bonding present in the $\mathrm{CN}_{x}$ films. ${ }^{4-9,11,18-23}$ However, the complex nature of the spectra and the lack of pure phases make their interpretation rather controversial. Baker and Hammer ${ }^{7}$ have developed a model of the $\mathrm{CN}_{x}$ microstructure that enables the chemical state assignment of up to eight components of the $\mathrm{C} 1 s$ spectrum. However, their differences in binding energies are so small that only four are usually distinguished in the experiments. Apparently the $\mathrm{N} 1 s$ spectra are simpler and their interpretation in terms of three components is rather general, however there still exists some controversy on the assignment of the carbonitrile bonding. A similar problem is observed in the interpretation of the IR spectra where the assignment of broad overlapping bands associated with $s p$ and $s p^{2}$ hybridized $\mathrm{C}-\mathrm{C}$ and $\mathrm{C}-\mathrm{N}$ bonds is rather ambiguous.

The film deposition technique considered here is dual ion beam sputtering. The use of energetic ions to assist the deposition is expected to enhance the incorporation of nitrogen in the films. We present a complete characterization of the films in terms of Fourier transform infrared spectroscopy (FT-IR), XPS Auger electron spectroscopy, (AES) depth profiling, electron energy loss spectroscopy (EELS) and atomic force microscopy (AFM). The study is mainly focused on the investigation of the influence of the deposition parameters, mainly bombarding energy and beam current density, on the nitrogen content and the structure of the $\mathrm{CN}_{x}$ films obtained by dual ion beam sputtering (DIBS).

\section{EXPERIMENT}

Carbon nitride thin films have been deposited in a DIBS system. The method consists of the deposition of carbon via $\mathrm{Ar}^{+}$sputtering of a graphite target using a $3 \mathrm{~cm}$ Kaufmann ion source at an angle of incidence of $45^{\circ}$, whereas an end
Hall ion source ( $2 \mathrm{~cm}$ exit diameter) is used for simultaneous bombardment of the growing film with $\mathrm{N}_{2}^{+}$ions, that impinge the film at $60^{\circ}$ off normal. $\mathrm{Si}(100)$ wafers after cleaning in a solution of HF and methanol (1:1 volume) and freshly cleaved $\mathrm{KCl}$ have been used as substrates. The temperature of the substrates was held at $200{ }^{\circ} \mathrm{C}$ during deposition. The base and working pressures of the system were $1 \times 10^{-7}$ and $3 \times 10^{-4}$ Torr, respectively. The deposition parameters have been summarized in Table I. The sputtering conditions of the graphite target (i.e., $500 \mathrm{eV}, 1 \mathrm{~mA} / \mathrm{cm}^{2} \mathrm{Ar}^{+}$ions, $5 \mathrm{~h}$ deposition time) were kept constant for all the films. With these conditions, a constant flux of $1.5 \times 10^{14}\left(\mathrm{C}\right.$ atoms $\left./ \mathrm{cm}^{2} \mathrm{~s}\right)$ has been obtained at the substrates, as determined after Rutherford backscattering spectrometry calibration of a nonassisted film. On the contrary, the current density $J_{N}$ of the $\mathrm{N}_{2}^{+}$assisting ions was varied according to the values collected in Table I. Unfortunately, those changes in the current density required also small changes $(55-89 \mathrm{eV})$ in the energy of the $\mathrm{N}_{2}^{+}$beam. The ion to atom arrival rate ratio (ARR) is presented in Table I in units of $\mathrm{N}_{2}^{+}$ions/C atoms.

FT-IR spectra were recorded in a Bruker IFS66V FTIR spectrometer between 7000 and $560 \mathrm{~cm}^{-1}$ with a resolution of $4 \mathrm{~cm}^{-1}$. Spectra were referred to a previously collected spectrum of a pure $\mathrm{KCl}$ substrate.

XPS and AES analysis have been performed in a PHI3027 spectrometer equipped with a double pass cylindrical mirror analyzer (CMA). For XPS the CMA has been operated at a pass energy of $50 \mathrm{eV}$ and the radiation source was nonmonochromatized $\operatorname{Mg} K_{\alpha} \quad$ x-ray radiation $(h \nu$ $=1253.6 \mathrm{eV})$. A quantitative estimate of the composition, i.e., N/C atomic ratio, was performed in terms of the relative intensity of the respective $1 s$ XPS signals and the sensitivity factors supplied by the manufacturer. ${ }^{24}$ The results are included in Table I. The spectra were charge corrected using the position of the $\mathrm{O} 1 s$ line. A primary electron beam of 3 $\mathrm{keV}$ was used for Auger analysis, while $2 \mathrm{keV} \mathrm{Ar}^{+}$ions rastered over an area of $2 \mathrm{~mm} \times 2 \mathrm{~mm}$ were used to obtain the in-depth profile of the films. The $K L L$ Auger peaks of C, $\mathrm{N}$, and $\mathrm{O}$ as well as $\mathrm{Si}(L M M)$ were monitored as a function of the sputtering time. The Auger spectra were recorded in the integral $\mathrm{N}(E)$ mode but the respective intensities were measured as the peak to peak height of the derivative spectra. Both surface and in-depth analysis were performed for all the samples. The relative thickness of the films was determined 


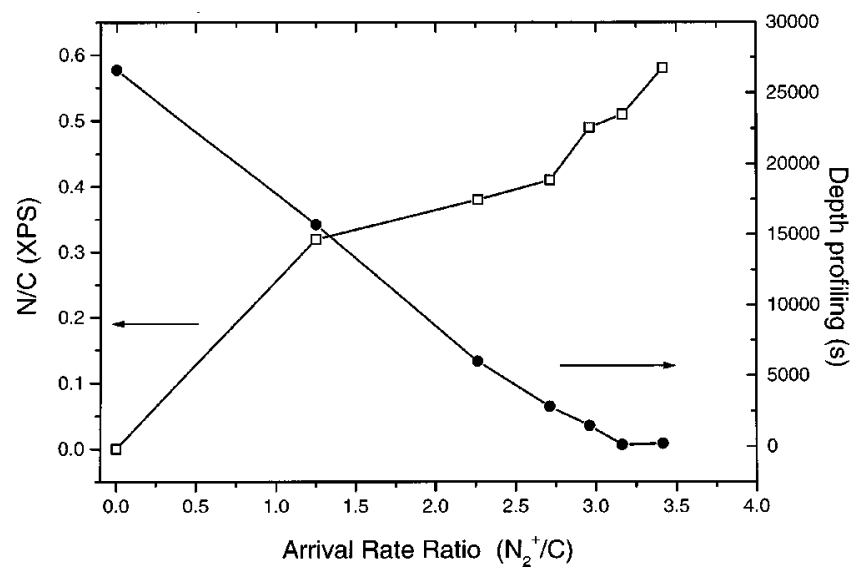

FIG. 1. N/C atomic ratio as stated by XPS and sputtering times of the complete AES depth profiles of the different $\mathrm{CN}_{x}$ films as a function of the ARR

by AES sputter depth profiling measuring the time needed to completely sputter the film (i.e., time at which the C KLL signal reduces to $50 \%$ of the steady state value) and assuming that the sputtering behavior of all the samples was the same during its depth profiling.

The films were also examined in a Philips CM 200 FEG microscope equipped with a GATAN GIF imaging system. The films were floated off in water and then supported on a copper grid coated with a holey carbon film. The EELS spectra were acquired in transmission mode with the GIF system at an accelerating voltage of $200 \mathrm{kV}$. The energy resolution was about $0.8 \mathrm{eV}$ and the illuminated area 1-2 $\mu \mathrm{m}$. Quantitative analysis was performed using the Gatan EL/P software.

The morphology of the $\mathrm{CN}$ films was examined with a home built AFM working in air and using the lever deflection method. The piezo was calibrated by imaging highly oriented pyrolitic graphite and silicon grids $(2 \mu \mathrm{m} \times 2 \mu \mathrm{m}$ and $5 \mu \mathrm{m} \times 5 \mu \mathrm{m}$ ). Two types of cantilevers from Park Scientific, triangular and rectangular shaped with spring constants 0.05 and $0.01 \mathrm{~N} / \mathrm{m}$, respectively, were used. All images were acquired without filtering in the constant force mode, taking simultaneously friction and topographic images.

\section{RESULTS}

Both the thickness and the nitrogen content of the $\mathrm{CN}_{x}$ films were observed to depend on the ARR, as can be seen in Fig. 1, where the surface N/C atomic ratio, stated by XPS, and the relative thickness of the films, obtained by AES depth profiling, are shown. When ARR increases, two effects are observed: the increase of the proportion of $\mathrm{N}$ atoms incorporated into the film and the continuous decrease of the thickness of the films. N/C rapid increase until saturation is reached at around $\mathrm{N} / \mathrm{C}=0.4$. Further increase of the ARR leads to the resputtering of the films.

Concerning the XPS estimated compositions, it is important to note that our films contain similar fractions of nitrogen as those observed by other authors. ${ }^{6,8,19,20}$ AES depth profiling demonstrated that the relative nitrogen concentration was constant along the film. The oxygen content was very low in the bulk of the film but increased slightly at the surface due to the exposure of the films to the atmosphere. The N/C atomic ratio can also be estimated from the intensities of the carbon and nitrogen $K$ edges of the EELS spectra (cf. Sec. III C). The respective results are summarized in Table I. The discrepancies with respect to the XPS data, mainly at high ARR, could arise from matrix effects that can affect EELS measurements that give information coming from the whole volume of the film. In addition, XPS surface measurements could be affected by the presence of small amounts of adventitous carbon that could reduce the $\mathrm{N}$ signal.

Both XPS and EELS measurements also show that when the ARR is higher than $2.8 \mathrm{~N}_{2}^{+}$ions/C atoms, the films incorporate significant $\mathrm{Fe}, \mathrm{W}, \mathrm{Cr}$, and $\mathrm{Ni}$ impurities, coming from the assisting ion gun, and $\mathrm{K}$ and $\mathrm{Cl}$, coming from the $\mathrm{KCl}$ substrates, in increasing amounts as the current density of the beam of assistance is increased. The total amount of the metallic contaminants depended on the deposition parameters, but was always below 10 at. \% (up to $20 \%$ in sample A6, grown under extreme assistance conditions). Therefore, for practical purposes the ARR should be kept below 2.8 $\mathrm{N}_{2}^{+}$ions/C atoms. In this case, we obtain homogeneous films with N/C ratios on the order of 0.35 .

Taking into account that the sputtering conditions, i.e., the flux density of $\mathrm{C}$ atoms arriving to the substrate, were held constant during the deposition of all the samples, the continuous decrease of the thickness observed in Fig. 1 can only be explained by the existence of intense resputtering phenomena of the carbon nitride films grown under $\mathrm{N}_{2}^{+}$bombardment. The energies and fluxes used in this work to assist the sample are not expected to induce significant physical resputtering. ${ }^{25}$ In fact, the sputtering coefficient of graphite under argon bombardment is very low. ${ }^{26}$ However, if the carbon films are bombarded with nitrogen, chemical sputtering takes place through the reaction of the nitrogen ions with the atoms of the film, giving rise to the formation of volatile compounds, like $\mathrm{C}_{2} \mathrm{~N}_{2}, \mathrm{~N}_{2}, \mathrm{CNH}$, and $\mathrm{CNOH}^{25,27,28}$ According to Fig. 1, it seems that for values of the ARR above 3.0, such resputtering phenomena are very intense and the growth process is clearly hindered. A simple growth model ${ }^{29}$ enables us to estimate that the resputtering coefficients of carbon and nitrogen under $\mathrm{N}_{2}^{+}$bombardment are close to 0.3 and 1.95 , respectively. This high value of the resputtering coefficient of nitrogen confirms the difficulties of incorporating nitrogen into the films.

\section{A. FT-IR}

Figure 2 shows the FT-IR transmission spectra of different films (as labeled) deposited on $\mathrm{KCl}$ according to the deposition conditions given in Table I. The contribution of the substrate was previously subtracted. The spectra appear characterized by two intense vibration bands: a broad absorption peak spanning from 1150 up to $1750 \mathrm{~cm}^{-1}$, which apparently has two major components at 1300 and 1500 


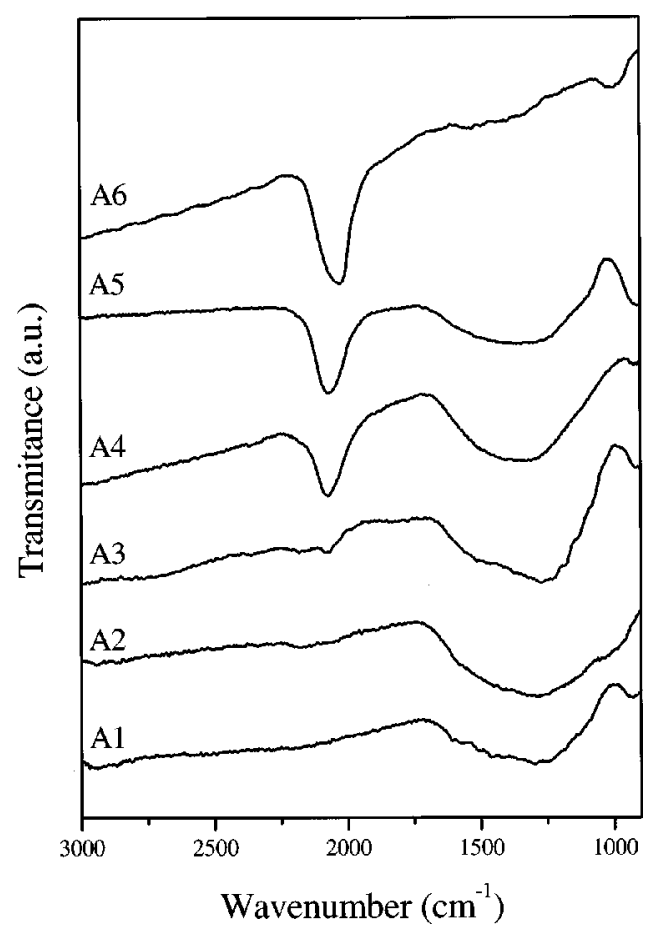

FIG. 2. FT-IR spectra of different $\mathrm{CN}_{x}$ samples as labeled (cf. Table I).

$\mathrm{cm}^{-1}$ and a much sharper peak, centered at $2060 \mathrm{~cm}^{-1}$. Another very weak contribution is also observed at around 2170 in some of the samples, especially in A2 and A3. The former is the main band that appears in the IR spectrum of samples A1 and A2. The band around $2060 \mathrm{~cm}^{-1}$, however, is clearly observable in $\mathrm{A} 3$ and grows along the successive samples (i.e., A3-A6) with increasing $\mathrm{N}_{2}^{+}$assistance and becomes the predominant feature in sample A6. The appearance and continuous growth of the band at $2060 \mathrm{~cm}^{-1}$ is the main effect to be observed in Fig. 2. It clearly indicates the formation of a new bonding type that modifies the basic structure of samples A1 and A2.

The interpretation of the broad absorption band around $1300 \mathrm{~cm}^{-1}$ has been given by Kaufman et al. ${ }^{30}$ in terms of the well known bands observed by Raman spectroscopy in graphite. These authors attribute the IR band at 1300 and $1500 \mathrm{~cm}^{-1}$ to different carbon vibrations, mostly to $\mathrm{C}-\mathrm{C}$, $\mathrm{C}=\mathrm{C}, \mathrm{C}-\mathrm{N}$, and $\mathrm{C}=\mathrm{N}$ vibrations in an amorphous network of threefold and fourfold coordinated carbon (i.e., $s p^{2}$ and $s p^{3}$ ). The band centered at $2060 \mathrm{~cm}^{-1}$, clearly separated from the region of singly and doubly bonded carbon, is attributed to a vibration mode of some $\mathrm{C} \equiv \mathrm{N}$ carbonitrile containing compound. ${ }^{18-20,30} \mathrm{In}$ fact, the position of this band is close to that of KCN, compound that has an intense absorption at around $2080 \mathrm{~cm}^{-1} \cdot{ }^{31}$ The progressive increase of the intensity of this peak when the assisting conditions increase can be related to the incorporation to the film of $\mathrm{K}$ atoms from the substrate activated by the ion bombardment, and is consistent with the progressive thinning of the films. Finally, the position of the small band at 2170 fits with that of carbodiimides $(-\mathrm{N}=\mathrm{C}=\mathrm{N}-) .{ }^{19}$ According to this interpretation, which is generally accepted, the IR spectra of samples

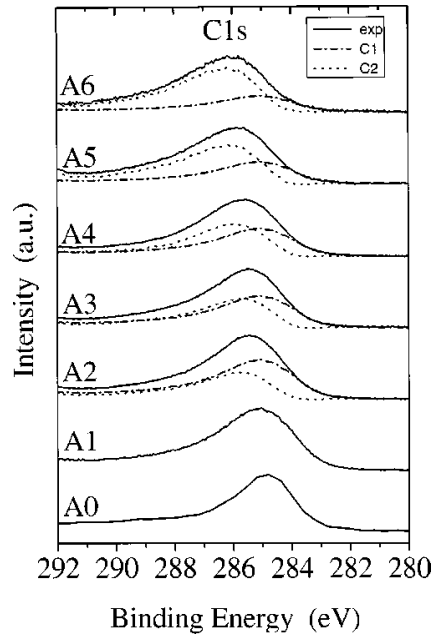

FIG. 3. Experimental C $1 s$ XPS spectra (full line) of different $\mathrm{CN}_{x}$ films as labeled (cf. Table I). Dashed line: C1 contribution proportional to A1 spectrum. Dotted line: C2 contribution increasing with nitrogen content.

$\mathrm{A} 1, \mathrm{~A} 2$, and $\mathrm{A} 3$ suggest that $\mathrm{N}$ is mainly bonded to $s p^{2}$ and $s p^{3}$ hybridized $\mathrm{C}$, as if the incorporated $\mathrm{N}$ were substituting the $\mathrm{C}$ atoms to form an extended inorganic $\mathrm{CN}_{x}$ carbon nitride solid. The intensity of the carbonitrile absorption in these three samples is weak, but it has to be taken into account that this absorption is strongly dependent on the matrix where the carbonitrile groups are embedded, so that FTIR can be underestimating the carbonitrile concentration. As the assisting conditions are increased, through samples A4, A5, and $\mathrm{A} 6$, the $\mathrm{CN}_{x}$ film does not grow and the band associated with $s p$ hybridization of $\mathrm{C}$ and $\mathrm{N}$ emerges and becomes almost the only absorption band in the IR spectrum of sample A6, probably related to the formation of $\mathrm{KCN}$.

\section{B. XPS}

XPS spectroscopy has been extensively used to study the incorporation of nitrogen and to address the chemical nature of $\mathrm{CN}_{x}$, i.e., to determine the bonding type. ${ }^{4-9,11,22,23}$

The respective $\mathrm{C} 1 s$ XPS spectra for different carbon nitride samples, as labeled (cf. Table I) are shown in Fig. 3. The changes in both the position of the maximum and the line shape of the spectrum are clearly observable, however its analysis is rather controversial. Usually the $\mathrm{C} 1 s$ spectra are analyzed in terms of several components that are assigned to different $\mathrm{C}-\mathrm{N}$ bonds based on the data for organic molecules that include the respective type of bonding. However, the variety of organic molecules and their dispersion in binding energies are large enough to make the assignment ambiguous and speculative. In fact, the consideration of all the possible $\mathrm{C}$ environments leads to so many overlapping components, (i.e., up to eight according to Baker $e t a l^{7}$ ), that they cannot be unambiguously deconvoluted. Therefore, we have preferred to analyze the experimental spectra (i.e., full line in Fig. 3) in terms of the spectrum corresponding to the sample grown with lower assistance, A1, which is the starting point of the set of samples, so that we can observe the part of the spectrum which grows (i.e., component $\mathrm{C} 2$, dotted 


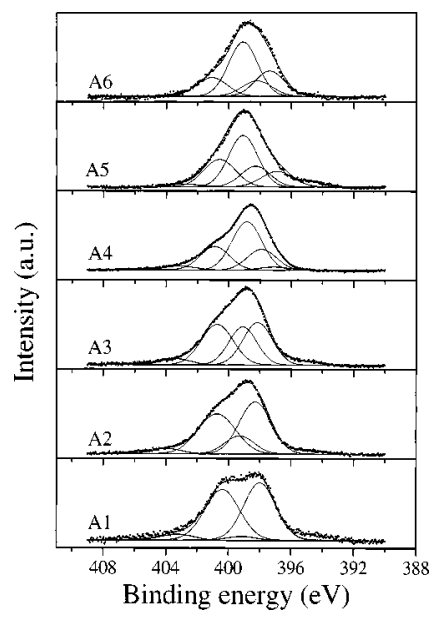

FIG. 4. XPS spectra of the $\mathrm{N} 1 s$ line for different $\mathrm{CN}_{x}$ samples as labeled. Experimental spectra and the components used in the deconvolution are shown.

line in Fig. 3) as a function of the deposition conditions or the increasing nitrogen content of the films. The deconvolution of every experimental spectrum has been depicted in Fig. 3, where the dashed lines (labeled C1) represent a contribution that is proportional to that of sample A1, and the dotted lines (labeled C2) show the contribution that increases with the assistance and the nitrogen content. A further analysis of these contributions is difficult and ambiguous as no new features are clearly distinguished. However, the evolution of both contributions clearly indicates that increasing the nitrogen content of the film leads to the growth of existing components or to the formation of new bonding types with higher binding energies.

Very commonly, the C $1 s$ XPS peak is analyzed in terms of four contributions that shift around $1 \mathrm{eV}$ between each other. According to Boyd, Marton et al. ${ }^{6}$ and Souto et al. ${ }^{23}$ the main components should be assigned to $\mathrm{C}-\mathrm{C}$ bonds at $284.6 \mathrm{eV}, \mathrm{C}-\mathrm{N}$ peaks at $286.6 \mathrm{eV}$, and at 287.3 for trigonal $s p^{2}$ and tetragonal $s p^{3}$ bonded carbon, respectively, and $\mathrm{C}-\mathrm{O}$ bonds around $290 \mathrm{eV}$. Other authors ${ }^{21,22}$ have also identified the $\mathrm{C} \equiv \mathrm{N}$ triple bond at $286.3 \mathrm{eV}$ very close to the peak associated with the trigonal $\mathrm{C}-\mathrm{N}$ bond. Therefore, it appears that the components corresponding to the nitrogen substituted bonds would contribute to the high energy tail of the spectrum, which would explain the increasing asymmetry of the peaks when the nitrogen content is increased, and which is in agreement with our results.

The N $1 s$ XPS spectra also show important line shape changes for the different samples. The dependence is shown in Fig. 4 for the same films as those represented in Fig. 3. The changes in the $\mathrm{N} 1 s$ line shape may also be understood as due to changes in the population of the different nitrogen bonding states. In this case, however, the main changes appear to occur at binding energies around $399 \mathrm{eV}$, i.e., in the middle of the spectrum. The experimental spectra have been deconvoluted using three principal components at 398.1, 399.1, and $400.7 \mathrm{eV}$, designed as N1, N2, and N3, respectively. The assignment of these components to definite

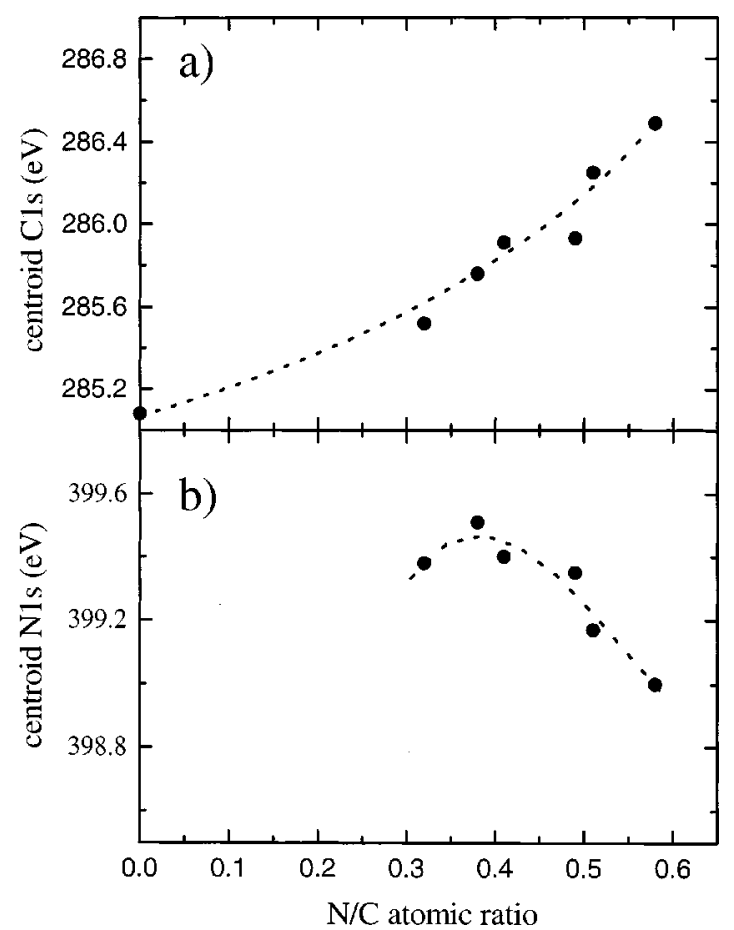

FIG. 5. Centroid of the C $1 s$ peak (a) and N $1 s$ peak (b) as a function of the $\mathrm{N} / \mathrm{C}$ atomic ratio.

chemical states is not unique, (i.e., many nitrogen species give $\mathrm{N} 1 s$ binding energies in the range $398-401 \mathrm{eV}$ ), but there is a general agreement to assign the peak at lower binding energy, $\mathrm{N} 1$ at $398.1 \mathrm{eV}$, to $\mathrm{N}-s p^{3} \mathrm{C}$ bonds, and the peak at higher binding energy, $\mathrm{N} 3$, to $\mathrm{N}-s p^{2} \mathrm{C}$ bonds. The peak at $399.1 \mathrm{eV}, \mathrm{N} 2$, can be associated with the formation of carbonitrile-like bonds due to $s p$ configurations (i.e., $\mathrm{C} \equiv \mathrm{N}){ }^{11,22}$ It has been necessary to include a small contribution at energies close to $403 \mathrm{eV}$, which accounts for the presence of $\mathrm{N}_{2}$ or $\mathrm{N}-\mathrm{O}$ species. ${ }^{4,5}$ Finally, for samples A4, $\mathrm{A} 5$, and $\mathrm{A} 6$, another component around $397 \mathrm{eV}$ has been used, assigned to the formation of metallic nitrides (due to the metallic impurities present in these samples, as mentioned before).

The binding energy of the centroid of the spectra, i.e., $\mathrm{BE}$ (centroid) $=\int N(E) E d E / \int N(E) d E$, where $N(E)$ is the intensity of the spectrum at every energy, is observed to shift as the nitrogen content varies. The centroid of the respective $\mathrm{C} 1 s$ peaks have been depicted in Fig. 5(a) as a function of the nitrogen content of the film, which corresponds to the assisting conditions as indicated in Table I. The maximum shift of the centroid corresponds to sample A6 and accounts for $1.4 \mathrm{eV}$ with respect to that measured in amorphous carbon and more than $1 \mathrm{eV}$ with respect to that of sample A1. It is worth mentioning that, according to the IR data, the spectrum for sample A6 is mainly due to $\mathrm{C} \equiv \mathrm{N}$ states, whose binding energy results very close to the values reported for $\mathrm{C}=\mathrm{N}$ in $\mathrm{C} 1 s$, which could explain the controversy existing in the literature with respect to these species.

Figure 5(b) shows the respective centroids for the $\mathrm{N} 1 \mathrm{~s}$ spectra as a function of the nitrogen content of the film. 


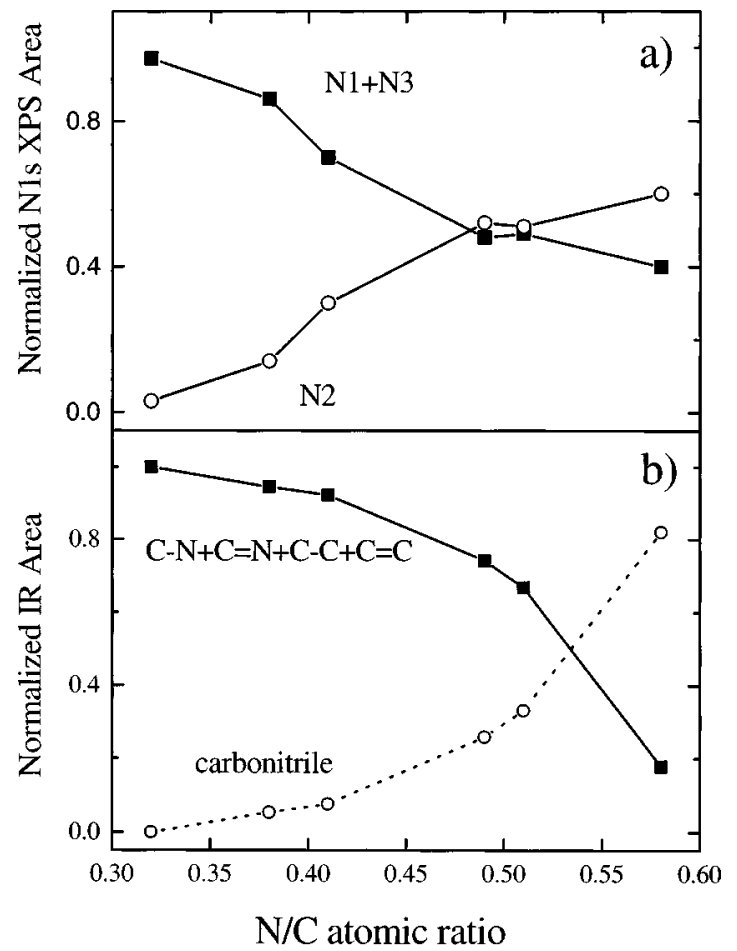

FIG. 6. Evolution of the intensity of the $(\mathrm{N} 1+\mathrm{N} 3)$ and $\mathrm{N} 2$ contributions to the $\mathrm{N} 1 s$ XPS signal (a) and of the $\mathrm{C}-\mathrm{N}+\mathrm{C}-\mathrm{C}+\mathrm{C}=\mathrm{N}+\mathrm{C}=\mathrm{C}$ and $\mathrm{C} \equiv \mathrm{N}$ to the FT-IR spectra (b), as a function of N/C atomic ratio.

Interestingly, the observed value of the shift for $\mathrm{N} 1 s$ (i.e., $0.5 \mathrm{eV}$ ) is smaller than that measured for $\mathrm{C} 1 s$ and in the opposite direction (i.e., towards lower binding energies) with respect to the spectrum for A1, i.e., for N/C above 30 at. \%. The opposite behavior of both shifts indicates a decrease of covalency and an increase of the charge transfer when the nitrogen content increases.

As in the case of the previous FT-IR characterization, the XPS results indicate that the carbon nitride films are a mixture of various carbon phases. The relationship between the concentration of the different phases and the nitrogen concentration of the films is consistent, at least qualitatively, with that of IR spectra. Figure 6(a) shows the peak areas of the N $1 s$ components associated with $\mathrm{N} 1$ and N3 contributions and the intensity of the component $\mathrm{N} 2$, assigned to $\mathrm{C} \equiv \mathrm{N}$, normalized to the $\mathrm{N} 1+\mathrm{N} 2+\mathrm{N} 3$ area, as a function of the nitrogen content in the film as given by XPS. For comparison, Fig. 6(b) shows the equivalent data as obtained from the IR spectra, i.e., the intensity of the absorption band associated with singly + doubly bounded carbon and that assigned to the carbonitrile-like bond. The comparison suggests the correlation between components N2 of XPS spectra and the carbonitrile band of the FTIR. The quantitative agreement between both techniques is rather poor, but the trend pointed out by both techniques is similar, the $\mathrm{C} \equiv \mathrm{N}$ nitrile-like structure replaces both the $\mathrm{N}-\mathrm{C} s p^{3}$ and $\mathrm{N}-\mathrm{C} s p^{2}$ bonds as the assisting parameters are increased and the formation of some interface layer takes place. The quantitative discrepancies between FTIR and XPS could be due to the fact that we are including $\mathrm{C}-\mathrm{C}$ and $\mathrm{C}=\mathrm{C}$ bonds in the FTIR

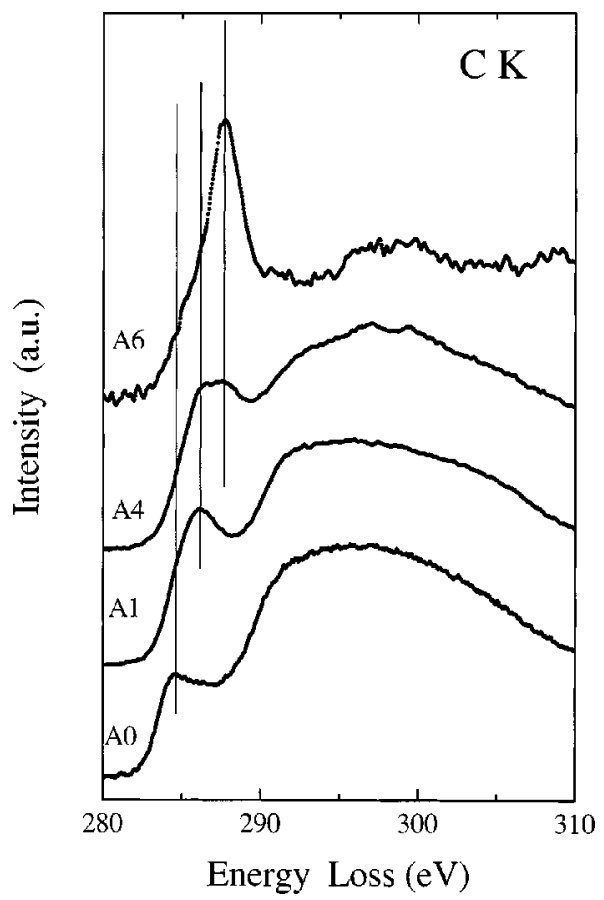

FIG. 7. EELS spectra at the $\mathrm{C} K$ edge of evaporated carbon, A0, and different $\mathrm{CN}_{x}$ samples, A1, A4, and A6.

spectra but also to different matrix effects in both techniques (as mentioned in Sec. III A). In addition, the changes in the background of the FTIR spectra also make difficult the correct quantification of the FTIR areas.

The evolution of features $\mathrm{N} 1$ and $\mathrm{N} 3$ indicates that the peak at the higher binding energy, i.e., $\mathrm{N} 3$, nitrogen $s p^{2}$ bonded, becomes slightly dominant in the films when the nitrogen content increases, suggesting that the $\mathrm{N} s p^{3}$ bonded is preferentially sputtered or replaced. As the growth of $\beta-\mathrm{C}_{3} \mathrm{~N}_{4}$ requires the formation of covalent $\mathrm{C}-\mathrm{N}$ bonds the above results indicate that increasing the assisting conditions to incorporate more nitrogen to the films leads to the formation of ionic bonds of the nitrile type instead of the desired $\mathrm{C}_{3} \mathrm{~N}_{4}$.

\section{EELS}

In Fig. 7 we have depicted the $C K$ edge EELS spectra for three $\mathrm{CN}_{x}$ samples (i.e., A1, A4, and A6) and for amorphous carbon $A_{0}$. This carbon film was obtained by evaporation of graphite and shows a typical spectrum with the characteristic $\mathrm{C} 1 s-\pi^{*}$ transition peaking at $285 \mathrm{eV}$ energy loss (due to $\mathrm{C}=\mathrm{C}$ bonds), followed by a very broad resonance centered around $297 \mathrm{eV}$, mainly due to $\mathrm{C} 1 s-\sigma^{*}$ transitions in the $\mathrm{C}-\mathrm{C}$ and $\mathrm{C}=\mathrm{C}$ bonds. The spectrum for the nitrogenated sample A1 is rather similar to that for amorphous carbon if the $1 s-\pi^{*}$ resonance at 285 is substituted by a new $\pi^{*}$ resonance at $286 \mathrm{eV}$, which indicates the formation of $\mathrm{N}=\mathrm{C}$ bonds with $\mathrm{C}$ in the $s p^{2}$ hybridization. ${ }^{4,32}$ A contribution at $285 \mathrm{eV}$, reminiscent of the amorphous carbon, can still be distinguished. The shape of the edge clearly suggests a similar graphite-like $s p^{2}$ structure, but shifted in energy due to the formation of $\mathrm{C}-\mathrm{N}$ bonds and a higher $\mathrm{C} 1 s$ binding en- 
ergy. Further increase in the assisting parameters leads to significant changes in the EELS spectra, as those shown for samples A4 and A6. In general we observe a continuous decrease of the $\mathrm{C} 1 s-\sigma^{*}$ transition as well as the growth of a new peak at $287.5 \mathrm{eV}$ that becomes the main feature in the spectrum for sample A6. This peak is assigned to a $\mathrm{C} 1 s-\pi^{*}$ transition in $\mathrm{C} \equiv \mathrm{N}$ bonds, i.e., with $\mathrm{C}$ in $s p$ hybridization, in good agreement with the previous discussion of the FTIR and XPS spectra that clearly indicated the formation of carbonitrile groups.

The spectrum of sample A6 resembles that of polyacrylonitrile, ${ }^{4}$ dominated by a sharp $\pi^{*}$ transition at $287.2 \mathrm{eV}$. In the case of sample A4, the $\pi^{*}$ resonance becomes a doublet due to at least two different carbon corelevel energies corresponding to carbon in different bonding sites with respect to the nitrogen atoms, i.e., at $286(\mathrm{C}=\mathrm{N})$ and $287.5(\mathrm{C} \equiv \mathrm{N})$.

These results can be compared with those obtained by XPS and FT-IR. In fact, for sample A4 the relative intensity of the two main contributions [i.e., $\mathrm{C}-\mathrm{N}+\mathrm{C}=\mathrm{N}$ and $\mathrm{C} \equiv \mathrm{N}$, see Fig. 6(a)] observed by the different techniques is rather similar. Furthermore, in the case of sample A6 we can observe that the $\pi^{*}$ resonance at $287.5 \mathrm{eV}$ dominates the spectrum indicating that, in good agreement with the FT-IR and XPS results presented previously, the $\mathrm{C} \equiv \mathrm{N}$ bond originates in this resonance. It is also in good agreement with a $\pi^{*}$ $\left(\mathrm{C}_{3} \mathrm{~N}\right)$ transition reported by Lopez et al. ${ }^{4}$ EELS also indicates the presence of metallic impurities in sample A6, indicating that the presence of $\mathrm{C} \equiv \mathrm{N}$ bonds could be related not only to the high nitrogen content in that film or to the presence of $\mathrm{KCN}$ but also to the existence of those metallic impurities.

Figure 8 shows the nitrogen $K$ edges for the same samples as in Fig. 7. It can be seen that the edge appears similar to the respective carbon edges. The spectra show two predominant transitions, the $1 s-\pi^{*}$ (due to $\mathrm{C}=\mathrm{N}$ and/or $\mathrm{C} \equiv \mathrm{N}$ ) and the $1 s-\sigma^{*}$. Interestingly, the $1 s-\pi^{*}$ peak in sample A1 is very broad. Zhu et al. ${ }^{33}$ suggest that the broadening they observe in the nitrogen $x$-ray absorption near edge spectra of pyridine-like compounds is due to the presence of different structural environments for the nitrogen incorporated in the graphene layers. Another possible contribution to these broad transitions could come from the presence of interstitial $\mathrm{N}$, as it has been proposed by Jiménez et al. ${ }^{34}$ for two peaks observed around 396 and $401 \mathrm{eV}$ in the nitrogen near-edge $\mathrm{x}$-ray absorption structure (NEXAFS) spectra of boron nitride.

Increasing the nitrogen content above $\mathrm{N} / \mathrm{C}=0.4$ leads to the growth of a new peak at $395.6 \mathrm{eV}$ again associated with the increase of carbonitrile groups (i.e., $s p$ hybridization). The increase of the relative intensity of the $\pi^{*}$ to the $\sigma^{*}$ transition observed in these spectra correlates well with the FT-IR and XPS information, and can be explained by the decrease of the proportion of $\mathrm{C}-\mathrm{N}$ bonds in the sample. Finally, sample A6, as its FTIR spectrum indicates, has contributions coming mainly from $\mathrm{C} \equiv \mathrm{N}$ bonds, consequently, its $1 s-\pi^{*}$ transition at $395.6 \mathrm{eV}$ and its $1 s-\sigma^{*}$ transition at

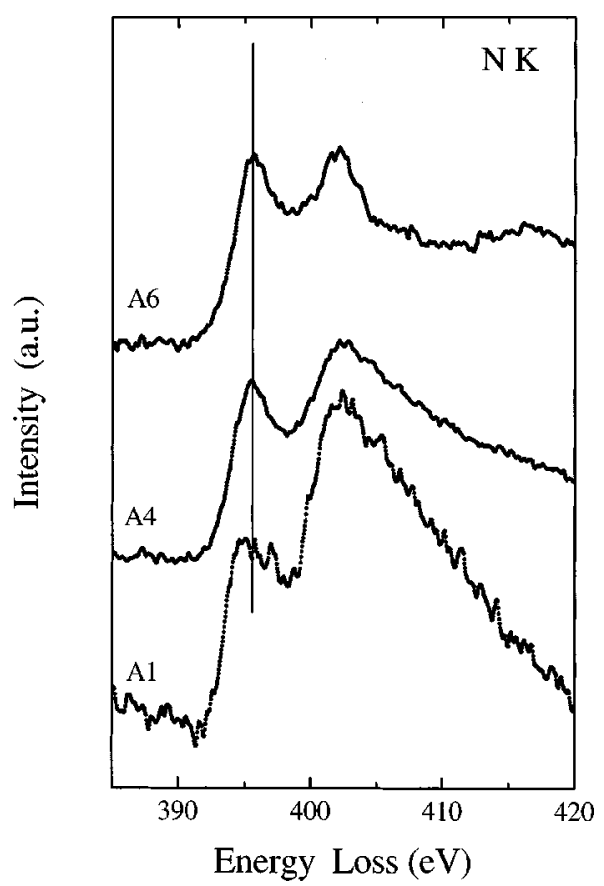

FIG. 8. EELS spectra at the $\mathrm{N} K$ edge for different $\mathrm{CN}_{x}$ films, $\mathrm{A} 1, \mathrm{~A} 4$, and A6.

around $402.1 \mathrm{eV}$ can be assigned to nitrogen triply bonded to carbon, i.e., $s p$ hybridized nitrogen.

\section{AFM Images}

Representative $2 \mu \mathrm{m} \times 2 \mu \mathrm{m}$ AFM images of the different $\mathrm{CN}_{x}$ films deposited on $\mathrm{KCl}$ are shown in Fig. 9. They show rather clearly the evolution of the film morphology as the ARR increases.

It is interesting to observe that for ARR lower than 2.4 (samples A1 and A2) the films present a homogeneous grain structure. The grain size increases with ARR probably because the surface mobility of the atoms arriving at the film is enhanced by the ion bombardment.

However, at intermediate values of ARR (i.e., between 2.4 and 3.0, corresponding to samples A3 and A4) the films develop deep valleys and intestine-like features, probably associated with the preferential resputtering of the graphite phases, as indicated by the XPS, EELS, and FT-IR information, and also to the sputtering of the $\mathrm{KCl}$ substrates. The morphology of these samples resembles that induced in polyurethane after bombardment with Ar ions. ${ }^{35}$

At ARR higher than 3.0 (samples A5 and A6), the damage and resputtering effects are very significant, leading to the disappearance of the previous texture. In fact the films are very thin and the morphology seems to be dominated by the sputtering of the $\mathrm{KCl}$ substrate.

\section{CONCLUSIONS}

Thin $\mathrm{CN}_{x}$ films have been obtained by DIBS. The films have been characterized as a function of the deposition parameters by FT-IR, XPS, EELS, AES depth profiling, and AFM. 


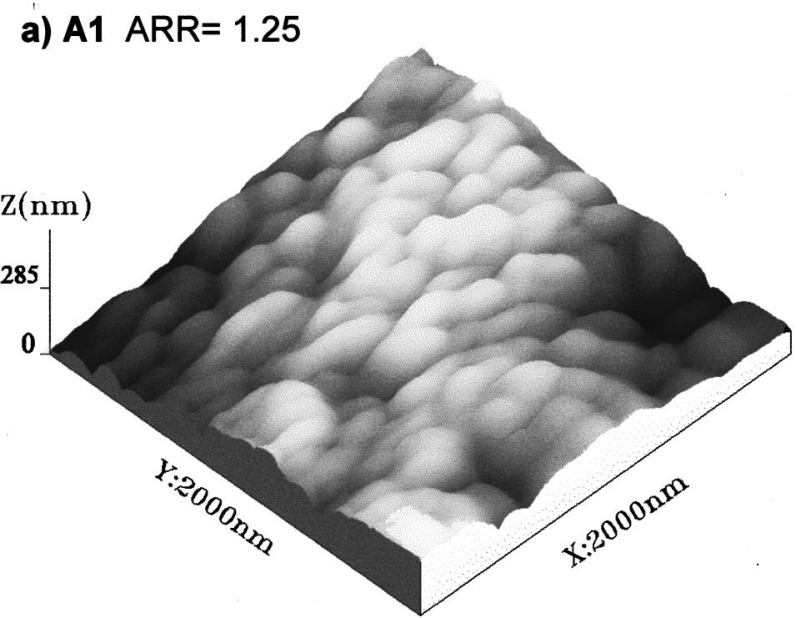

\section{b) $\mathrm{A} 2 \mathrm{ARR}=2.26$}

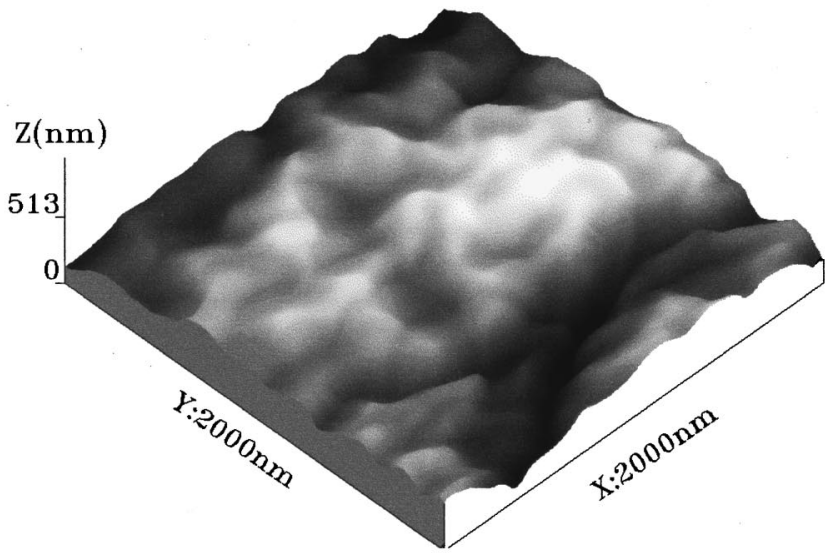

c) A3 $\mathrm{ARR}=2.71$
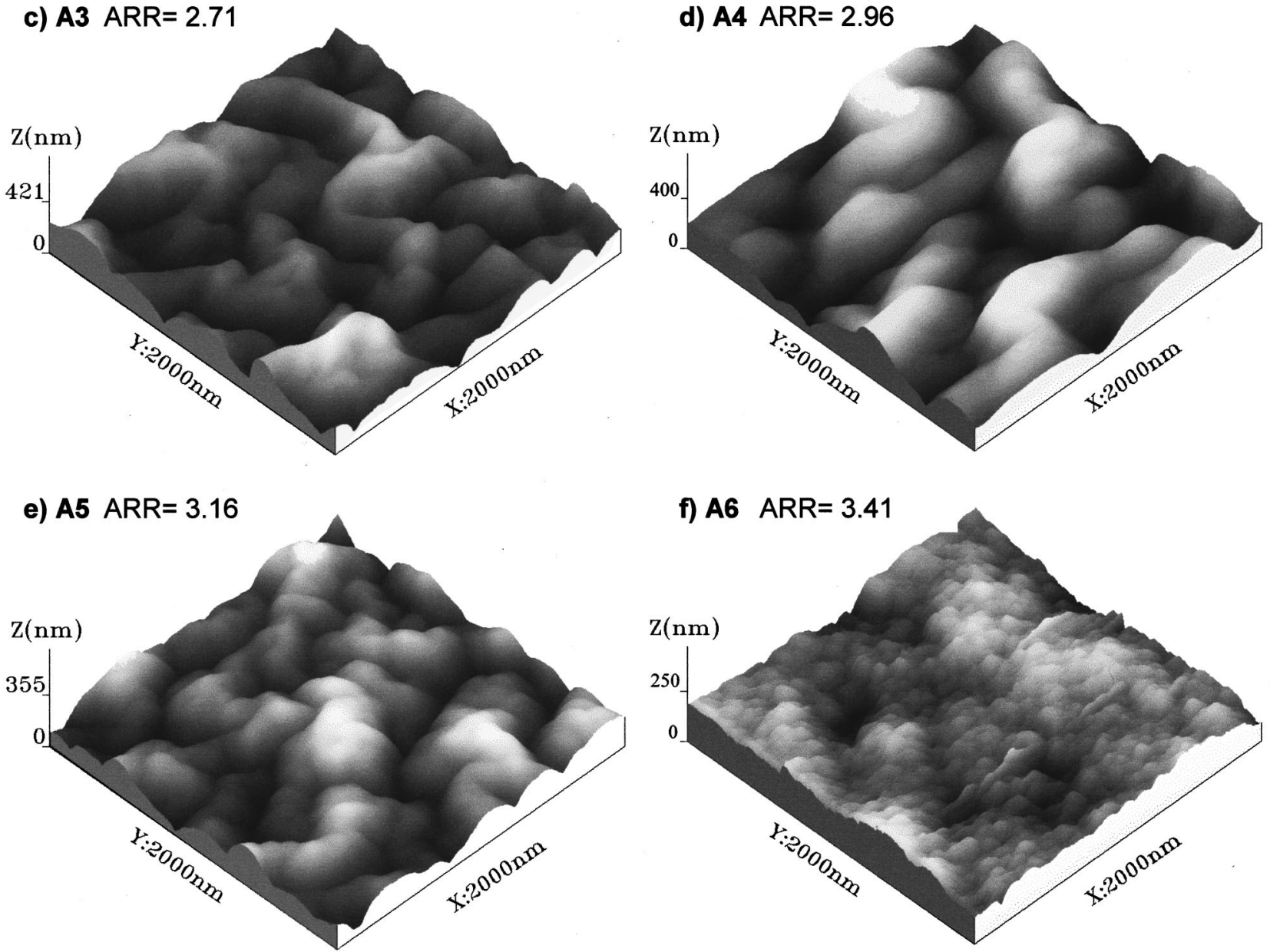

FIG. 9. $2 \mu \mathrm{m} \times 2 \mu \mathrm{m}$ AFM images of different $\mathrm{CN}_{x}$ films as labeled.

The nitrogen content of the films has been observed to depend on the current density and energy of the assisting nitrogen ions. In fact, it appears that $\mathrm{N} / \mathrm{C} \approx 0.4$ is a limit for an $\mathrm{N}$-doped amorphous $\mathrm{C}$ structure with reasonable thickness, which agrees with the experimental evidence, pointed out by other authors. ${ }^{7}$

FT-IR, XPS and EELS indicate that the nitrogen content and the type of bonding of the amorphous $\mathrm{CN}_{x}$ synthesized material are strongly correlated to the assisting parameters. At low doses of $\mathrm{N}_{2}^{+}$assistance, ARR $<2.4$, films are mainly formed by a combination of $\mathrm{C}-\mathrm{N}$ and $\mathrm{C}=\mathrm{N}$ bonding, embedded in a graphite like structure with $\mathrm{C}-\mathrm{C}$ and $\mathrm{C} \equiv \mathrm{C}$ bonds. Increasing the assisting conditions leads to films with increasing amounts of $\mathrm{C} \equiv \mathrm{N}$ bonds, probably associated with the formation of $\mathrm{KCN}$, with a higher nitrogen content and intense resputtering phenomena that reduce significantly the 
thickness of the samples and hinders the growth of the film. Values of ARR higher than 3.0 result in the formation of very thin films. The morphology of the films has also been investigated by AFM as a function of the deposition parameters.

Features associated with $\mathrm{C} \equiv \mathrm{N}$ bonds in the XPS and EELS spectra of $\mathrm{C}$ and $\mathrm{N}$ signals have been identified using the fact that, under the experimental conditions employed in this work, we produced films with increasing amounts of carbonitrile groups, as FT-IR spectra suggest.

${ }^{1}$ A. Y. Liu and M. L. Cohen, Phys. Rev. B 41, 10727 (1990).

${ }^{2}$ A. Y. Liu and M. L. Cohen, Science 245, 841 (1989).

${ }^{3}$ C. Niu, Y. Z. Lu, and C. M. Lieber, Science 261, 334 (1993).

${ }^{4}$ S. Lopez, H. M. Dunlop, M. Benmalek, G. Tourillon, M.-S. Wong, and W. D. Sproul, Surf. Interface Anal. 25, 315 (1997).

${ }^{5}$ H. Sjöström, L. Hultman, J.-E. Sundgren, S. V. Hainsworth, T. F. Page, and G. S. A. M. Theunissen, J. Vac. Sci. Technol. A 14, 56 (1996).

${ }^{6}$ K. J. Boyd, D. Marton, S. S. Todorov, A. H. Al-Bayati, J. Kulik, R. A. Zhur, and J. W. Rabalais, J. Vac. Sci. Technol. A 13, 2110 (1995).

${ }^{7}$ M. A. Baker and P. Hammer, Surf. Interface Anal. 25, 301 (1997).

${ }^{8}$ A. Bousetta, M. Lu, and A. Bensaoula, J. Vac. Sci. Technol. A 13, 1639 (1995).

${ }^{9}$ M. Ricci, M. Trinquecoste, F. Auguste, R. Canet, P. Delhaes, C. Guimon, G. Pfister-Guillouzo, B. Nysten, and J. P. Issi, J. Mater. Res. 8, 480 (1993).

${ }^{10}$ W. Dawei, F. Dejun, G. Huaixi, Z. Zhilong, M. Xianquan, and Fan Xiangjun, Phys. Rev. B 56, 4949 (1997).

${ }^{11}$ I. Gouzman, R. Brener, and A. Hoffman, Surf. Sci. 331-333, 283 (1995).

${ }^{12}$ Z.-M. Ren, Y.-C. Du, Z.-F. Ying, Y.-X. Qiu, X.-X. Xiong, J.-D. Wu, and F.-M. Li, Appl. Phys. Lett. 65, 1361 (1994).

${ }^{13}$ K. M. Yu, M. L. Cohen, E. E. Haller, W. L. Hansen, A. L. Liu, and I. C. Wu, Phys. Rev. B 49, 5034 (1994).

${ }^{14}$ C. Quirós, R. Núñez, P. Prieto, E. Elizalde, A. Fernández, M. Schubert, C. Donnet, and J. M. Sanz, Vacuum 52, 199 (1999).

${ }^{15}$ W.-C. Chan, B. Zhou, Y.-W. Chung, C. S. Lee, and S. T. Lee, J. Vac. Sci. Technol. A 16, 1907 (1998).
${ }^{16}$ H. Jensen, J. Sobota, and G. Sorensen, J. Vac. Sci. Technol. A 16, 1880 (1998).

${ }^{17}$ A. Y. Liu and R. M. Wentzcovitch, Phys. Rev. B 50, 10362 (1994).

${ }^{18}$ X. A. Zhao, C. W. Ong, Y. C. Tsang, Y. W. Wong, P. W. Chan, and C. L. Choy, Appl. Phys. Lett. 66, 2652 (1995).

${ }^{19}$ F. R. Weber and H. Oeschner, Surf. Coat. Technol. 74-75, 704 (1995).

${ }^{20}$ Z. J. Zhang, S. Fan, and C. M. Lieber, Appl. Phys. Lett. 66, 3582 (1995).

${ }^{21}$ K. Ogata, J. F. Diniz Chubaci, and F. Fujimoto, J. Appl. Phys. 76, 3791 (1994).

${ }^{22}$ S. Kumar, K. S. A. Butcher, and T. L. Tansley, J. Vac. Sci. Technol. A 14, 2687 (1996).

${ }^{23}$ S. Souto, M. Pickholz, M. C. dos Santos, and F. Alvarez, Phys. Rev. B 57, 2536 (1998).

${ }^{24}$ J. F. Moulder, W. F. Stickle, P. E. Sobol, and K. D. Bomben, in Handbook of X-ray Photoelectron Spectroscopy, edited by J. Chastain (PerkinElmer, Eden Prairie, 1992).

${ }^{25}$ P. Hammer, M. A. Baker, C. Lenardi, and W. Gissler, Thin Solid Films 290-291, 107 (1996).

${ }^{26}$ B. A. Banks, in Handbook of Ion Beam Processing Technology, edited by J. J. Cuomo, S. Rossnagel and H. R. Kaufman (Noyes, Park Ridge, 1989), pp. 339-340.

${ }^{27}$ R. Kaltofen, T. Sebald, and G. Weise, Thin Solid Films 290-291, 112 (1996).

${ }^{28}$ S. S. Todorov, D. Marton, K. J. Boyd, A. H. Al-Bayati, and J. W. Rabalais, J. Vac. Sci. Technol. A 12, 3192 (1994).

${ }^{29}$ C. Quirós, P. Prieto, E. Elizalde, R. Pérez-Casero, V. Gómez, P. Herrero, and J. M. Sanz, Surf. Coat. Technol. (to be published).

${ }^{30}$ J. Kaufman, S. Metin, and D. D. Saperstein, Phys. Rev. B 39, 13053 (1989).

${ }^{31}$ L. J. Bellamy in The Infrared Spectra of Complex Molecules (Chapman and Hall, Cambridge, 1975), Vol. 1, p. 390.

${ }^{32}$ A. Fernandez, P. Prieto, C. Quirós, J. M. Sanz, J.-M. Martin, and B. Vacher, Appl. Phys. Lett. 69, 764 (1996).

${ }^{33}$ Q. Zhu, S. L. Money, A. E. Rusell, and K. M. Thomas, Langmuir 13, 2149 (1997).

${ }^{34}$ I. Jiménez et al., Appl. Phys. Lett. 68, 2816 (1996).

${ }^{35}$ B. A. Banks, in Ion Bombardment Modification of Surfaces. Fundamentals and Applications, edited by O. Auciello and R. Kelly (Elsevier, Amsterdam, 1984), p. 406. 